\title{
Drive the Car(go)s-New Modalities to Control Cargo Trafficking in Live Cells
}

\author{
Payel Mondal ${ }^{1}$, John S. Khamo ${ }^{1}$, Vishnu V. Krishnamurthy ${ }^{1}$, Qi Cai ${ }^{1}$ and Kai Zhang ${ }^{1,2,3 *}$ \\ ${ }^{1}$ Department of Biochemistry, University of Illinois at Urbana-Champaign, Urbana, IL, USA, ${ }^{2}$ Neuroscience Program, \\ University of Illinois at Urbana-Champaign, Urbana, IL, USA, ${ }^{3}$ Center for Biophysics and Quantitative Biology, \\ University of Illinois at Urbana-Champaign, Urbana, IL, USA
}

Synaptic transmission is a fundamental molecular process underlying learning and memory. Successful synaptic transmission involves coupled interaction between electrical signals (action potentials) and chemical signals (neurotransmitters). Defective synaptic transmission has been reported in a variety of neurological disorders such as Autism and Alzheimer's disease. A large variety of macromolecules and organelles are enriched near functional synapses. Although a portion of macromolecules can be produced locally at the synapse, a large number of synaptic components especially the membrane-bound receptors and peptide neurotransmitters require active transport machinery to reach their sites of action. This spatial relocation is mediated by energyconsuming, motor protein-driven cargo trafficking. Properly regulated cargo trafficking is of fundamental importance to neuronal functions, including synaptic transmission. In this review, we discuss the molecular machinery of cargo trafficking with emphasis on new experimental strategies that enable direct modulation of cargo trafficking in live

OPEN ACCESS

Edited by:

Jiajie Diao,

University of Cincinnati, USA

Reviewed by:

Yong Wang,

University of Arkansas, USA

Ruoyi Qiu,

Stanford University, USA

*Correspondence:

Kai Zhang

kaizkaiz@illinois.edu

Received: 08 November 2016 Accepted: 05 January 2017 Published: 20 January 2017

Citation:

Mondal P, Khamo JS, Krishnamurthy W, Cai $Q$ and

Zhang K (2017) Drive the

Car(go)s-New Modalities to Control

Cargo Trafficking in Live Cells.

Front. Mol. Neurosci. 10:4. doi: 10.3389/fnmol.2017.00004 cells. These strategies promise to provide insights into a quantitative understanding of cargo trafficking, which could lead to new intervention strategies for the treatment of neurological diseases.

Keywords: synaptic transmission, neurological disorders, cargo trafficking, motor proteins, axonal transport, optogenetics, chemically induced dimerization, photoactivatable proteins

\section{INTRODUCTION}

The human brain has approximately 86 billion neuronal cells (Azevedo et al., 2009), each of which possesses a large number of synapses to other cells. For instance, each neocortical neuron has an average of about 7000 synapses for exchanges of information (Pakkenberg et al., 2003). Synaptic transmission, which relays information from one cell to the next via coupled events between electrical and chemical signals through synapses, plays a crucial role in learning and memory consolidation. In response to cell depolarization (electrical signals), neurotransmitters (chemical signals) are released into the synaptic cleft, bind to their postsynaptic receptors and trigger downstream signaling activities in the postsynaptic cell. Defective synaptic transmission causes a variety of neurological disorders (van Spronsen and Hoogenraad, 2010) and cognitive diseases (Lau and Zukin, 2007; Südhof, 2008).

Quantitative analysis of synapses has found that, in addition to neurotransmitters, many other molecules and organelles are enriched in the synapse. These molecules include receptors and channels, cytoskeleton, kinases and phosphatases and their regulators, GTPases and their regulators, motor proteins, scaffolding proteins, components of signaling and membrane 
trafficking, and mitochondria (Ziv and Garner, 2004; Sheng and Hoogenraad, 2007; Bourne and Harris, 2008; Margeta et al., 2008). Indeed, proteomic studies have revealed that more than 2000 different proteins reside in the synapse (Dieterich and Kreutz, 2016). A portion of these synaptic components are likely to be synthesized locally, given that components of translation machinery, e.g., polyribosomes, reside in dendritic shafts and spines. Indeed, it has been shown that rapid dendritic protein synthesis occurs during metabotropic glutamate receptor (mGluR)-dependent long-term depression (LTD; Huber et al., 2000). De-centralized protein synthesis has been an emerging paradigm in studying how neurons achieve specific functions and signals that occur in highly compartmentalized subcellular domains (Holt and Schuman, 2013). Many crucial synaptic components, however, cannot be produced locally in the synapse (Kennedy and Ehlers, 2006). These components include neurotrophin receptors (Ascaño et al., 2009), dense core vesicles, synaptic vesicle precursors (Goldstein et al., 2008) and neurotransmitter receptors (Kneussel and Loebrich, 2007; Shepherd and Huganir, 2007). Biogenesis of these macromolecules often occurs at a great distance from the synapse. The extremely polarized neuronal morphology excludes access of these macromolecules to synapses based on diffusion. As a result, these synaptic components require energy-consuming, motor protein-driven trafficking mechanism to reach their sites of action (Schlager and Hoogenraad, 2009). Thus, a functional synapse requires properly regulated cargo trafficking.

In this review article, we discuss basic cargo trafficking machinery with emphasis on the recently developed strategies that allow active manipulation of cargo trafficking in live cells. Here, cargo trafficking is defined as the process that involves motor-protein-driven transport along cytoskeletons, in contrast to trafficking involved in neuronal activity-regulated cargo endocytosis, exocytosis or lateral diffusion within the plasma membrane. The biotechnological advances discussed herein promise to generate new insights into the understanding of synapse building, synaptic transmission and neurological diseases.

\section{BASIC COMPONENTS OF CARGO TRAFFICKING}

Cargo trafficking is mediated through the interaction of the vesicle with the cytoskeletal tracks. Basic components of cargo trafficking include cargos (vehicles), motor proteins (wheels), cytoskeleton (road) and energy (fuel).

\section{Cargos}

In axons, cargos travel through either fast or slow axonal transport (Vallee and Bloom, 1991). Cargos that travel through fast axonal transport have an average speed of about $0.5-5 \mathrm{micron} / \mathrm{s}(40-400 \mathrm{~mm} /$ day $)$. Synaptic vesicles and enzymes for neurotransmitter metabolism use anterograde transport (from the cell body to the axon terminal); internalized membrane receptors and neurotrophins use retrograde transport (from the axon terminal to the cell body); organelles such as mitochondria travel in both anterograde and retrograde directions through engagement of motor adaptor proteins such as trafficking kinesin protein (TRAK)/Milton (van Spronsen et al., 2013). Cargos that travel through slow axonal transport have an average speed of $0.3-8 \mathrm{~mm} /$ day. These cargos include "building materials" of neuronal cytoskeletons such as neurofilaments and microtubules, actins, spectrin and tau proteins. Both fast and slow axonal transport adopts a "stopand-go" pattern, i.e., cruising intersected by pausing (Brown, 2000). Intriguingly, the slow axonal transport is driven by "fast" motors, and the slow speed is due to prolonged pauses (Brown, 2003).

\section{Cytoskeleton and Motor Proteins}

Cargo trafficking depends on the interaction between cytoskeleton and motor proteins (Vale, 2003). The neuronal cytoskeleton is composed of microtubules, actin filaments and neurofilaments (Kevenaar and Hoogenraad, 2015). The main function of neurofilaments, enriched primarily in axons, is to control the axon diameter and axonal conductance (Yuan et al., 2012). Microtubules and actin filaments serve as tracks for motor proteins in axonal and dendritic shafts. On microtubules, kinesin superfamily motor proteins drive anterograde transport (Gennerich and Vale, 2009; Hirokawa et al., 2009); cytoplasmic dyneins drive retrograde transport. One type of motor protein can transport a variety of cargos. For instance, kinesin-1 transports components of cytoskeleton, mitochondria and Soluble NSF Attachment Protein Receptor (SNARE) proteins (Hirokawa and Noda, 2008). Such a specificity of transport can be achieved through splice variants of motor proteins (Cyr et al., 1991) or post translational modifications such as selective phosphorylation in kinesin light chain (Ichimura et al., 2002; Vagnoni et al., 2011). Myosins are a superfamily of motor proteins that travel along actin filaments (Mitchison and Cramer, 1996; Blanchoin et al., 2014). Recently, super-resolution microscopy showed that axonal actin is also organized in regularly spaced rings that wrap around the circumference of axons (Xu et al., 2013). This subpopulation of axonal actin is likely to provide mechanical support for the axon membrane and may not be involved in the myosin-dependent cargo trafficking.

\section{Energy}

Intriguingly, although mitochondria are the major organelles that provide energy to boost up molecular machineries in cells (Sheng, 2014), they may not be the energy resource for axonal transport. Instead, the energy is more likely to be supplied by ATP generated by vesicular glycolysis (Zala et al., 2013). Inhibition of ATP production from mitochondria via oligomycin, an inhibitor of mitochondrial $\mathrm{H}^{+}$-ATP-synthase, did not affect the fast axonal transport of brain-derived neurotrophic factor (BDNF). In contrast, treating cells with iodoacetate, which inhibits glyceraldehyde3-phosphate dehydrogenase (GAPDH), the key glycolytic enzyme, significantly reduced the average velocity of BDNF 
(Zala et al., 2013). On the other hand, although oligomycin had no effect on vesicle transport, it blocked mitochondria trafficking, consistent with previous findings that loss of mitochondrial ATP production induces loss of mitochondrial dynamics (Kaasik et al., 2007).

\section{TRACKING CARGO TRANSPORT IN LIVE CELLS}

Early work used radioactive labeling to detect cargo trafficking in neurons (Lasek, 1967; Ochs et al., 1969). Although this method confirmed the existence of fast and slow axonal transport, it lacked the resolution to track individual cargos. Video-enhanced contract-differential interference contrast microscopy (Brady et al., 1982) allowed for tracking of individual cargoes, but could not differentiate their identities. Advanced fluorescence microscopy techniques, such as single-molecule fluorescence microscopy, have enabled real-time tracking of neurotrophin transport in live neuronal cells (Tani et al., 2005). However, the data acquisition time was limited to tens of seconds owing to photobleaching of the organic fluorophore such as Cy3. More photostable probes such as semiconductor nanocrystals (quantum dots) allowed for continuous tracking of cargos along neuronal processes for several minutes over hundreds of microns (Cui et al., 2007). Although typical quantum dots (about $20 \mathrm{~nm}$ in diameter) are much larger than organic fluorophores, they did not seem to disturb the biological activity of neurotrophin (Cui et al., 2007). Recent development of small quantum dots (9 $\mathrm{nm}$ in diameter) will further improve their use in live cell imaging (Cai et al., 2014). A critical difference between in vitro and live-cell cargo trafficking is that intracellular trafficking is regulated not only by motor proteins, but also by cargo-organelle and cargo-cytoskeletal interactions. Evidence shows that early endosomal interaction with microtubule intersection, other early endosomes, and endoplasmic reticulum contributes to the pausing of epidermal growth factor-containing early endosomes (Zajac et al., 2013). To effectively determine the directionality of cargo trafficking, Campenot (1977) designed the first prototype of compartmentalized culturing device that separates the cell body from the distant neurite. Improved quality has been achieved by replacing Teflon with polydimethylsiloxane (PDMS), a transparent and highly biocompatible material (Taylor et al., 2005; Mudrakola et al., 2009; Zhang et al., 2011).

\section{RESTORATION OF CARGO TRAFFICKING EXERTS NEUROPROTECTIVE EFFECTS}

Defective cargo trafficking has been found in a variety of neurological disorders (Tischfield et al., 2011) and brain injury (Povlishock and Jenkins, 1995). For instance, huntingtinassociated protein 1 (HAP1) is highly expressed in neurons and mediates kinesin-based anterograde transport (McGuire et al., 2006). In Huntingtin disease, stronger interaction between huntingtin protein and HAP1 leads to detachment of molecular motors from BDNF-containing cargos and reduced BDNF transport (Charrin et al., 2005). Analysis of axonal transport defects in human disease has been comprehensively reviewed and will not be repeated here (Roy et al., 2005; Chevalier-Larsen and Holzbaur, 2006; De Vos et al., 2008; Morfini et al., 2009; Hirokawa et al., 2010; Hinckelmann et al., 2013). Notably, although the causality of defective cargo trafficking to neurological disorders is still under debate (Goldstein, 2012), multiple lines of research have provided evidence that restoration of axonal transport can exert neuroprotective effects (Hinckelmann et al., 2013). For instance, failed retrograde transport of nerve growth factor (NGF) from the hippocampus to the basal forebrain caused reduction in size and number of basal forebrain cholinergic neurons (BFCN) in the partial trisomy 16 (Ts65Dn) mouse model of Down's syndrome. Such defects were rescued by delivering NGF directly to the cell bodies of BFCN through intracerebroventricular administration, which bypassed defective axonal transport (Cooper et al., 2001). Reduction of the endogenous level of Tau, a microtubule-associated protein, ameliorated amyloid $\beta$-induced deficits in an Alzheimer's disease mouse model (Roberson et al., 2007). Tau reduction has also been shown to rescue defective axonal transport of mitochondria and neurotrophin receptors (Vossel et al., 2010). Modulation of tau-microtubule interactions has been proposed as a therapeutic strategy for the treatment of tauopathies (Ballatore et al., 2011). The majority of these studies used an indirect way (e.g., bypassing axonal transport or genetic modulation of microtubuleassociation protein) to rescue defective transport. It remains unknown if direct rescuing of cargo trafficking is sufficient to induce neuroprotective effects. Recent biotechnological advances have started to offer new opportunities to address this issue.

\section{DIRECT CONTROL OF CARGO TRAFFICKING IN LIVE CELLS}

Correct positioning of organelles plays a crucial role in signaling regulation, cell differentiation and development (van Bergeijk et al., 2016). For instance, localized positioning of endosomes contributes to polarization and local outgrowth of neuronal cells (Sadowski et al., 2009; Eva et al., 2010, 2012; Golachowska et al., 2010; Higuchi et al., 2014). Similarly, correct mitochondrial positioning helps in axon branching (Courchet et al., 2013; Spillane et al., 2013) and synaptic function (MacAskill et al., 2010; Sheng and Cai, 2012). Golgi positioning is crucial to axon specification and dendrite development (Yadav and Linstedt, 2011; Ori-McKenney et al., 2012). Active nuclear positioning ensures correct cellular function during cell division, migration and differentiation (Gundersen and Worman, 2013). Altered positioning of dynamic organelles in cells is involved in neurodegenerative disorders. For instance, perinuclear accumulation of lysosomes is increased in a cellular model of Huntington's disease (Erie et al., 2015). Taking advantages of accumulating knowledge of motor and scaffolding proteins involved in organelle transport 
A

Chemically induced dimerization

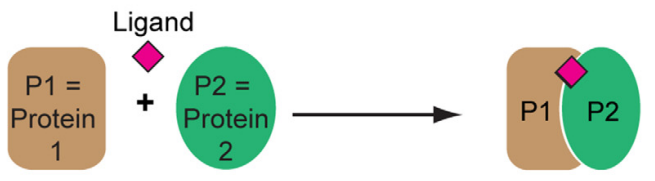

Protein $1=$ FKBP, Protein $2=$ FRB,

Ligand $=$ rapamycin

B

\section{Optochemical control \\ Ligand}

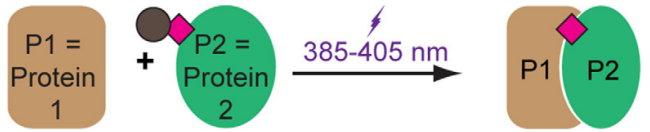

Protein $1=$ Haloenzyme, Protein $2=$ eDHFR,

Ligand $=$ cTMP-Htag

C

\section{Optogenetic control}

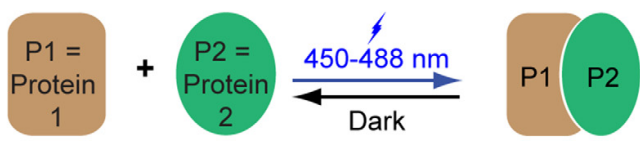

Protein $1=$ LOV-pep, Protein $2=$ ePDZ

Protein $1=\mathrm{CRY} 2$, Protein $2=\mathrm{CIB} 1$

D
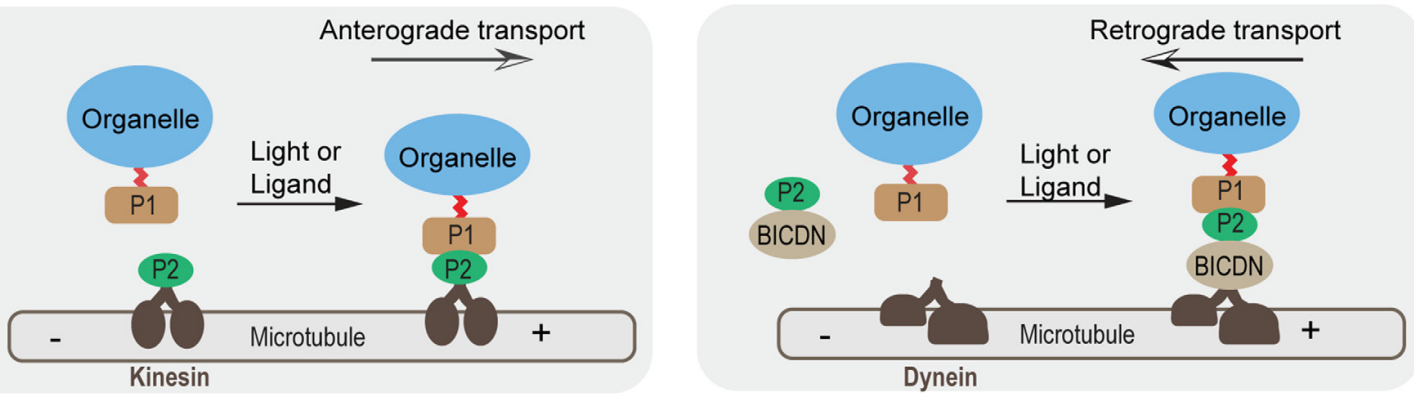

\section{E Magnetic control}
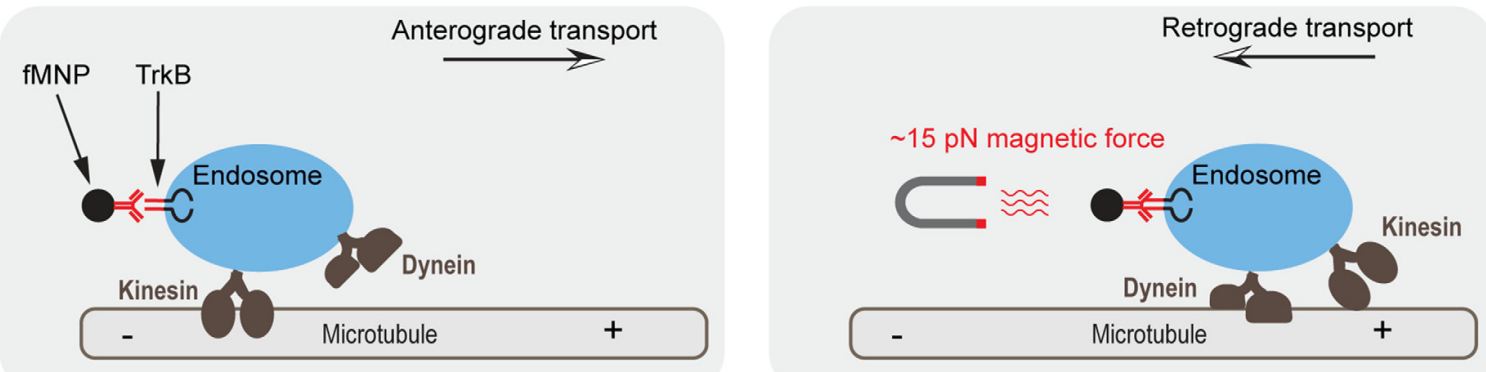

FIGURE 1 | Molecular mechanisms for controlling cargo tracking in cells. (A-C) Protein dimerization induced by chemically induced dimerization (CID) (A), optochemical (B) and optogenetic (C) approaches. (D) Cargo trafficking can be controlled by construction of fusion protein between motor proteins (such as kinesin), motor protein adapters (e.g., BICDN) and organelle-targeting signals with different combinations of protein pairs. (E) Control of endosome trafficking using magnetic nanoparticles functioned with antibody for TrkB. A force of $15 \mathrm{pN}$ reverses the direction of transport from anterograde to retrograde. FKBP, FK506 Binding Protein; FRB, FKBP Rapamycin Binding domain of mammalian target of rapamycin (mTOR); eDHFR, Escherichia coli dihydrofolate reductase, cTMP-Htag, photocaged trimethoprim-Halo tag, photocaged trimethoprim; LOV-pep, light, oxygen, voltage-peptide epitope; ePDZ, engineered PDZ domain; CRY2, Arabidopsis cryptochrome 2; CIB1, cryptochrome 2 interacting basic helix-loop-helix; BICDN, the amino terminus of bicaudal D homolog 2 (BICD2); TrkB, tropomyosin-related kinase B; fMNP, anti-TrkB functionalized superparamagnetic nanoparticle.

(Fu and Holzbaur, 2014), emerging new biotechnologies have enabled direct control of organelle trafficking in live cells with high spatiotemporal resolution and cargo specificity (Figure 1 and Table 1).

\section{Chemically Induced Dimerization (CID)}

Chemically induced dimerization (CID) uses a small molecule to induce binding between two proteins (Putyrski and Schultz, 2012; Rakhit et al., 2014; Voss et al., 2015; 
TABLE 1 | Summary of current controlling mechanisms for cargo trafficking in live cells.

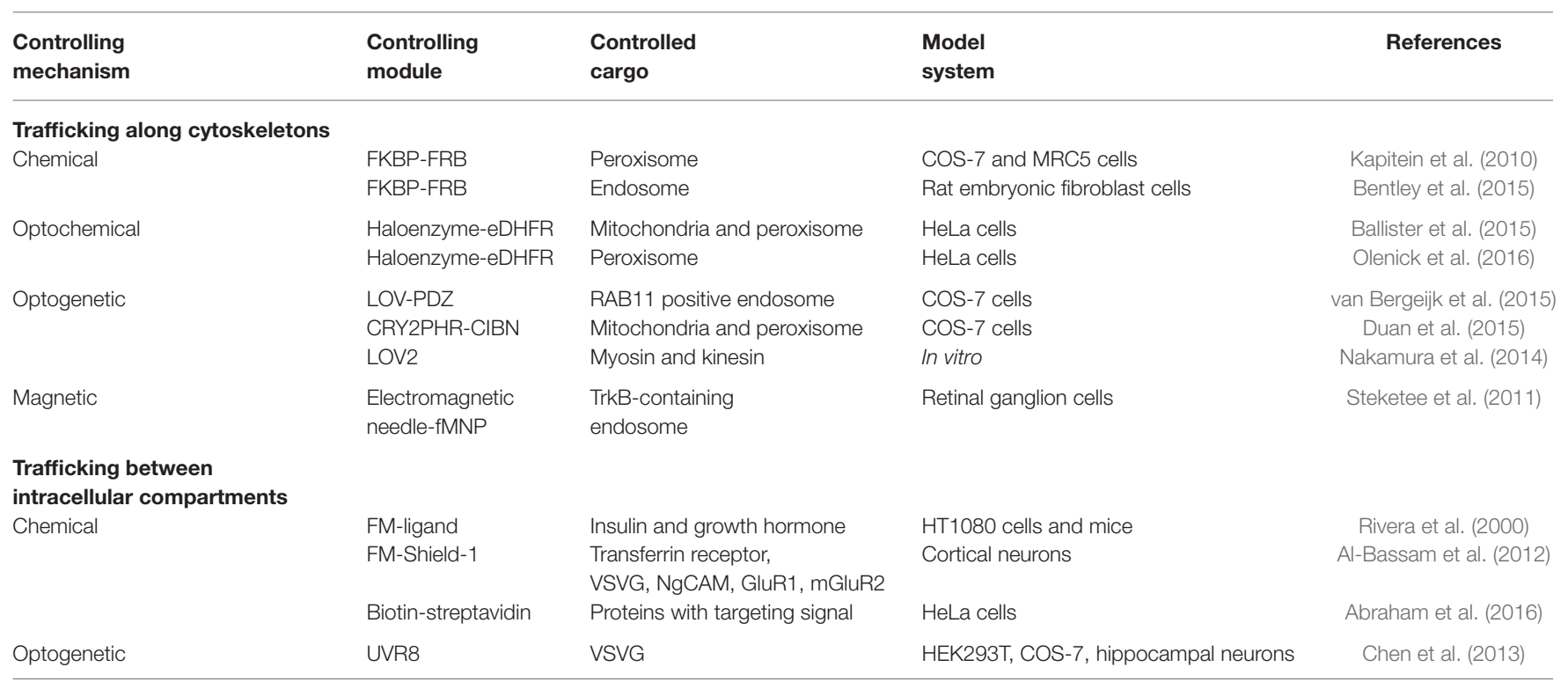

Figure 1A). A commonly used module is the rapamycin based FK506 Binding Protein (FKBP) and the FKBP Rapamycin Binding (FRB) domain of mammalian target of rapamycin (mTOR; Banaszynski et al., 2005; Inoue et al., 2005). This system has been used to recruit motor proteins (or their adapters) to peroxisomes to achieve rapamycin-induced transport along corresponding cytoskeletons (Kapitein et al., 2010). A similar scheme has also been used to position early endosomes or late endosomes by fusing the FKBP-FRB system to endosomal markers (Rab5 and Rab7) and motor proteins (Bentley et al., 2015).

\section{Optochemical Control}

An optochemical system utilizes a photoactivatable ligand to induce association of a pair of proteins (Figure 1B). One such ligand is cTMP-Htag, a synthetic, cell-permeant, small molecule comprising a Halotag ligand (a ligand for Haloenzyme) linked to photocaged trimethoprim (TMP), a ligand for Escherichia coli dihydrofolate reductase (eDHFR). A pulse of UV light uncages TMP and fully activates the dual-ligand, which crosslinks the Haloenzyme and the eDHFRfusion protein (Ballister et al., 2014). When applied in cells where eDHPR was fused to motors or motor effectors and Halotag was fused to cargos, eTMP-Htag enabled lightcontrolled crosslinking between cargos and motors (Ballister et al., 2015). This system has allowed for directional control of mitochondria or peroxisome trafficking in neurons. Other optochemical systems, such as those based on photocaged rapamycin (Karginov et al., 2011; Umeda et al., 2011), chemically modified abscisic acid (Wright et al., 2015; Zeng et al., 2015) and gibberellic acid (Schelkle et al., 2015), photoactivatable crosslinker for SNAPTag and HaloTag (Zimmermann et al., 2014), are also expected to achieve similar optochemical control.

\section{Optogenetic Control}

Optogenetics harnesses the power of light to modulate proteinprotein interactions in live cells (Figure 1C). Shortly after its initial success in controlling neuronal firing (Banghart et al., 2004; Boyden et al., 2005; Deisseroth, 2011), optogenetics has been extended to control other cellular processes such as gene transcription, translation, protein splicing, protein degradation, cell differentiation and cell death. The possibility of modulating signaling pathways and cell functions with high spatiotemporal precision offers an entirely new modality to dissect molecular mechanisms governing cell fate determination (Toettcher et al., 2011; Zoltowski and Gardner, 2011; Tucker, 2012; Kim and Lin, 2013; Tischer and Weiner, 2014; Zhang and Cui, 2015). Photoactivatable proteins have been used in multiple model systems including yeast (Shimizu-Sato et al., 2002; Tyszkiewicz and Muir, 2008; Hughes et al., 2012; Strickland et al., 2012), mammalian cells (Levskaya et al., 2009; Wu et al., 2009; Yazawa et al., 2009; Kennedy et al., 2010; Toettcher et al., 2011; Idevall-Hagren et al., 2012; Mills et al., 2012; Zhou et al., 2012; Bugaj et al., 2013; Grusch et al., 2014; Kim et al., 2014; Lee et al., 2014; Taslimi et al., 2014; Zhang et al., 2014; Hughes et al., 2015; Kawano et al., 2015; Yumerefendi et al., 2016), primary neurons (Chen et al., 2013; Kakumoto and Nakata, 2013; Konermann et al., 2013), Drosophila (Boulina et al., 2013), zebrafish embryos (Liu et al., 2012; Motta-Mena et al., 2014; Buckley et al., 2016) and Xenopus embryos (Krishnamurthy et al., 2016). To control cargo trafficking, photoactivatable proteins such as the light, oxygen, voltage-peptide epitope (LOV-pep) and engineered PDZ domain (ePDZ; van Bergeijk et al., 2015) or cryptochrome 2 (CRY2) and cryptochrome 2 interacting basic helix-loop-helix (CIB1; Duan et al., 2015) were fused to cargoes and motor proteins or motor adapters (Figure 1D). Interestingly, directionality of transport seems 
to depend on the load of motor proteins. By engineering the LOV domain into the lever arm of myosin or kinesin, the directionality of these motor proteins can be reversibly modulated as reported in a recent in vitro assay (Nakamura et al., 2014).

\section{Magnetic Control}

Another strategy utilizes magnetic force to reverse cargo transport. Using an electromagnetic needle and antibodyfunctionalized superparamagnetic nanoparticles (fMNPs), Steketee et al. (2011) could reverse the direction of transport of TrkB-containing endosomes in retinal ganglion cells (Figure 1E). Manipulation of fMNP signaling endosomes by a focal magnetic field altered growth cone motility and halted neurite outgrowth (Steketee et al., 2011).

Notably, trafficking along the secretory pathway between membrane-bound cellular compartments including the endoplasmic reticulum, Golgi apparatus, endosome and plasma membrane can also be controlled via chemical, optochemical and optogenetic strategies. The general strategy involves a chemical- or light-induced activation of the targeting signal, either by uncaging a blocking motif (Abraham et al., 2016) or inducing dissociation of a mislocalized protein cluster (Rivera et al., 2000; Al-Bassam et al., 2012; Chen et al., 2013). Interested readers are encouraged to refer to the references listed in Table 1.

\section{OUTSTANDING QUESTIONS AND FUTURE DIRECTIONS}

Cargo trafficking plays a crucial role in neuronal survival, differentiation, axon pathfinding, as well as synaptogenesis and synaptic transmission. With advances in genetic and protein engineering, single-molecule fluorescence microscopy, microfluidics, CID and optogenetics, one can control cargo trafficking with superior spatiotemporal resolution and molecular specificity. Because most of controlling systems are genetically encoded, it is possible to generate novel model systems harboring light- or chemical- sensitive signaling circuits. These tools could thus provide new perspectives to address

\section{REFERENCES}

Abraham, O., Gotliv, K., Parnis, A., Boncompain, G., Perez, F., and Cassel, D. (2016). Control of protein trafficking by reversible masking of transport signals. Mol. Biol. Cell 27, 1310-1319. doi: 10.1091/mbc.E15-07-0472

Al-Bassam, S., Xu, M., Wandless, T. J., and Arnold, D. B. (2012). Differential trafficking of transport vesicles contributes to the localization of dendritic proteins. Cell Rep. 2, 89-100. doi: 10.1016/j.celrep.2012. 05.018

Ascaño, M., Richmond, A., Borden, P., and Kuruvilla, R. (2009). Axonal targeting of Trk receptors via transcytosis regulates sensitivity to neurotrophin responses. J. Neurosci. 29, 11674-11685. doi: 10.1523/JNEUROSCI.1542-09. 2009

Azevedo, F. A. C., Carvalho, L. R. B., Grinberg, L. T., Farfel, J. M., Ferretti, R. E. L., Leite, R. E. P., et al. (2009). Equal numbers of neuronal and nonneuronal cells make the human brain an isometrically scaled-up primate brain. J. Comp. Neurol. 513, 532-541. doi: 10.1002/cne. 21974 controversies in the field of cargo trafficking in neuroscience. On the other hand, significant improvement of current technologies is needed before they can be successfully applied in tissues or multicellular organisms. For instance, single-molecule fluorescence microscopy has been mostly applied in vitro or in separated cells. Its potential in multicellular organisms has yet to be fully realized, owing to the limited penetration depth of visible light in the high-absorbing, high-scattering biological tissues. Poor penetration of visible light in biological tissues also results in invasiveness and low throughput of current optogenetic techniques, which often relies on insertion of fiber optics or microscale light emitting diodes arrays (Kim et al., 2013) in tissues for light delivery. Successful removal of these technical barriers requires a collaborative effort of researchers from multi-disciplinary fields including physics, material sciences, biochemistry and bioengineering. Shortly after the initial phase of tool development, as demonstrated in recent literature, we believe follow-up work will start to address the signaling outcomes in response to the modulated cargo trafficking. For instance, is defective cargo transport a cause or a result of misregulated neuronal functions and neurological disorders? Can we rescue defective neuronal phenotypes by direct modulation of cargo trafficking? We believe that biotechnological advances will continue pushing forward our understanding of the molecular machinery underlying neuronal survival, differentiation, repair and synaptic transmission and plasticity.

\section{AUTHOR CONTRIBUTIONS}

PM, JSK, VVK, QC and KZ performed literature search and wrote the initial draft. PM generated Table 1. QC designed and generated Figure 1. QC and KZ wrote the final manuscript.

\section{ACKNOWLEDGMENTS}

This work was supported by the University of Illinois at UrbanaChampaign. We apologize to those colleagues whose work could not be cited here owing to space limitations.

Ballatore, C., Brunden, K. R., Trojanowski, J. Q., Lee, V. M. Y., Smith, A. B. III., and Huryn, D. M. (2011). Modulation of protein-protein interactions as a therapeutic strategy for the treatment of neurodegenerative tauopathies. Curr. Top. Med. Chem. 11, 317-330. doi: 10.2174/156802611794072605

Ballister, E. R., Aonbangkhen, C., Mayo, A. M., Lampson, M. A., and Chenoweth, D. M. (2014). Localized light-induced protein dimerization in living cells using a photocaged dimerizer. Nat. Commun. 5:5475. doi: 10.1038/ncomms6475

Ballister, E. R., Ayloo, S., Chenoweth, D. M., Lampson, M. A., and Holzbaur, E. L. (2015). Optogenetic control of organelle transport using a photocaged chemical inducer of dimerization. Curr. Biol. 25, R407-R408. doi: 10.1016/j.cub.2015. 03.056

Banaszynski, L. A., Liu, C. W., and Wandless, T. J. (2005). Characterization of the FKBP.rapamycin.FRB ternary complex. J. Am. Chem. Soc. 127, 4715-4721. doi: $10.1021 /$ ja043277y

Banghart, M., Borges, K., Isacoff, E., Trauner, D., and Kramer, R. H. (2004). Lightactivated ion channels for remote control of neuronal firing. Nat. Neurosci. 7, 1381-1386. doi: 10.1038/nn1356 
Bentley, M., Decker, H., Luisi, J., and Banker, G. (2015). A novel assay reveals preferential binding between Rabs, kinesins and specific endosomal subpopulations. J. Cell Biol. 208, 273-281. doi: 10.1083/jcb.2014 08056

van Bergeijk, P., Adrian, M., Hoogenraad, C. C., and Kapitein, L. C. (2015). Optogenetic control of organelle transport and positioning. Nature 518, 111-114. doi: 10.1038/nature14128

van Bergeijk, P., Hoogenraad, C. C., and Kapitein, L. C. (2016). Right time, right place: probing the functions of organelle positioning. Trends Cell Biol. 26, 121-134. doi: 10.1016/j.tcb.2015.10.001

Blanchoin, L., Boujemaa-Paterski, R., Sykes, C., and Plastino, J. (2014). Actin dynamics, architecture and mechanics in cell motility. Physiol. Rev. 94, 235-263. doi: 10.1152/physrev.00018.2013

Boulina, M., Samarajeewa, H., Baker, J. D., Kim, M. D., and Chiba, A. (2013). Live imaging of multicolor-labeled cells in Drosophila. Development 140, 1605-1613. doi: 10.1242/dev.088930

Bourne, J. N., and Harris, K. M. (2008). Balancing structure and function at hippocampal dendritic spines. Annu. Rev. Neurosci. 31, 47-67. doi: 10.1146/annurev.neuro.31.060407.125646

Boyden, E. S., Zhang, F., Bamberg, E., Nagel, G., and Deisseroth, K. (2005). Millisecond-timescale, genetically targeted optical control of neural activity. Nat. Neurosci. 8, 1263-1268. doi: 10.1038/nn1525

Brady, S. T., Lasek, R. J., and Allen, R. D. (1982). Fast axonal-transport in extruded axoplasm from squid giant-axon. Science 218, 1129-1131. doi: 10.1126/science. 6183745

Brown, A. (2000). Slow axonal transport: stop and go traffic in the axon. Nat. Rev. Mol. Cell Biol. 1, 153-156. doi: 10.1038/35040102

Brown, A. (2003). Axonal transport of membranous and nonmembranous cargoes: a unified perspective. J. Cell Biol. 160, 817-821. doi: 10.1083/jcb.2002 12017

Buckley, C. E., Moore, R. E., Reade, A., Goldberg, A. R., Weiner, O. D., and Clarke, J. D. (2016). Reversible optogenetic control of subcellular protein localization in a live vertebrate embryo. Dev. Cell 36, 117-126. doi: 10.1016/j. devcel.2015.12.011

Bugaj, L. J., Choksi, A. T., Mesuda, C. K., Kane, R. S., and Schaffer, D. V. (2013). Optogenetic protein clustering and signaling activation in mammalian cells. Nat. Methods 10, 249-252. doi: 10.1038/nmeth.2360

Cai, E., Ge, P., Lee, S. H., Jeyifous, O., Wang, Y., Liu, Y., et al. (2014). Stable small quantum dots for synaptic receptor tracking on live neurons. Angew. Chem. Int. Ed. Engl. 53, 12484-12488. doi: 10.1002/anie.201405735

Campenot, R. B. (1977). Local control of neurite development by nerve growth factor. Proc. Natl. Acad. Sci. U S A 74, 4516-4519. doi: 10.1073/pnas.74. 10.4516

Charrin, B. C., Saudou, F., and Humbert, S. (2005). Axonal transport failure in neurodegenerative disorders: the case of Huntington's disease. Pathol. Biol. 53, 189-192. doi: 10.1016/j.patbio.2004.12.008

Chen, D., Gibson, E. S., and Kennedy, M. J. (2013). A light-triggered protein secretion system. J. Cell Biol. 201, 631-640. doi: 10.1083/jcb.2012 10119

Chevalier-Larsen, E., and Holzbaur, E. L. (2006). Axonal transport and neurodegenerative disease. Biochim. Biophys. Acta 1762, 1094-1108. doi: 10.1016/j.bbadis.2006.04.002

Cooper, J. D., Salehi, A., Delcroix, J. D., Howe, C. L., Belichenko, P. V., ChuaCouzens, J., et al. (2001). Failed retrograde transport of NGF in a mouse model of Down's syndrome: reversal of cholinergic neurodegenerative phenotypes following NGF infusion. Proc. Natl. Acad. Sci. U S A 98, 10439-10444. doi: 10.1073/pnas. 181219298

Courchet, J., Lewis, T. L. Jr., Lee, S., Courchet, V., Liou, D. Y., Aizawa, S., et al. (2013). Terminal axon branching is regulated by the LKB1-NUAK1 kinase pathway via presynaptic mitochondrial capture. Cell 153, 1510-1525. doi: 10.1016/j.cell.2013.05.021

Cui, B., Wu, C., Chen, L., Ramirez, A., Bearer, E. L., Li, W. P., et al. (2007). One at a time, live tracking of NGF axonal transport using quantum dots. Proc. Natl. Acad. Sci. U S A 104, 13666-13671. doi: 10.1073/pnas.07061 92104

Cyr, J. L., Pfister, K. K., Bloom, G. S., Slaughter, C. A., and Brady, S. T. (1991). Molecular-genetics of kinesin light-chains: generation of isoforms by alternative splicing. Proc. Natl. Acad. Sci. U S A 88, 10114-10118. doi: $10.1073 /$ pnas.88.22.10114
Deisseroth, K. (2011). Optogenetics. Nat. Methods 8, 26-29. doi: 10.1038/ nmeth.f.324

Dieterich, D. C., and Kreutz, M. R. (2016). Proteomics of the synapse-a quantitative approach to neuronal plasticity. Mol. Cell. Proteomics 15, 368-381. doi: 10.1074/mcp.R115.051482

Duan, L., Che, D., Zhang, K., Ong, Q., Guo, S., and Cui, B. (2015). Optogenetic control of molecular motors and organelle distributions in cells. Chem. Biol. 22, 671-682. doi: 10.1016/j.chembiol.2015.04.014

Erie, C., Sacino, M., Houle, L., Lu, M. L., and Wei, J. N. (2015). Altered lysosomal positioning affects lysosomal functions in a cellular model of Huntington's disease. Eur. J. Neurosci. 42, 1941-1951. doi: 10.1111/ejn. 12957

Eva, R., Crisp, S., Marland, J. R., Norman, J. C., Kanamarlapudi, V., ffrenchConstant, C., et al. (2012). ARF6 directs axon transport and traffic of integrins and regulates axon growth in adult DRG neurons. J. Neurosci. 32, 10352-10364. doi: 10.1523/JNEUROSCI.1409-12.2012

Eva, R., Dassie, E., Caswell, P. T., Dick, G., ffrench-Constant, C., Norman, J. C., et al. (2010). Rabl1 and its effector Rab coupling protein contribute to the trafficking of $\beta 1$ integrins during axon growth in adult dorsal root ganglion neurons and PC12 cells. J. Neurosci. 30, 11654-11669. doi: 10.1523/JNEUROSCI.2425-10.2010

Fu, M. M., and Holzbaur, E. L. (2014). Integrated regulation of motor-driven organelle transport by scaffolding proteins. Trends Cell Biol. 24, 564-574. doi: $10.1016 /$ j.tcb.2014.05.002

Gennerich, A., and Vale, R. D. (2009). Walking the walk: how kinesin and dynein coordinate their steps. Curr. Opin. Cell Biol. 21, 59-67. doi: 10.1016/j.ceb.2008. 12.002

Golachowska, M. R., Hoekstra, D., and van IJzendoorn, S. C. D. (2010). Recycling endosomes in apical plasma membrane domain formation and epithelial cell polarity. Trends Cell Biol. 20, 618-626. doi: 10.1016/j.tcb.2010. 08.004

Goldstein, L. S. (2012). Axonal transport and neurodegenerative disease: can we see the elephant? Prog. Neurobiol. 99, 186-190. doi: 10.1016/j.pneurobio.2012. 03.006

Goldstein, A. Y., Wang, X., and Schwarz, T. L. (2008). Axonal transport and the delivery of pre-synaptic components. Curr. Opin. Neurobiol. 18, 495-503. doi: 10.1016/j.conb.2008.10.003

Grusch, M., Schelch, K., Riedler, R., Reichhart, E., Differ, C., Berger, W., et al. (2014). Spatio-temporally precise activation of engineered receptor tyrosine kinases by light. EMBO J. 33, 1713-1726. doi: 10.15252/embj.2013 87695

Gundersen, G. G., and Worman, H. J. (2013). Nuclear positioning. Cell 152, 1376-1389. doi: 10.1016/j.cell.2013.02.031

Higuchi, Y., Ashwin, P., Roger, Y., and Steinberg, G. (2014). Early endosome motility spatially organizes polysome distribution. J. Cell Biol. 204, 343-357. doi: $10.1083 /$ jcb. 201307164

Hinckelmann, M. V., Zala, D., and Saudou, F. (2013). Releasing the brake: restoring fast axonal transport in neurodegenerative disorders. Trends Cell Biol. 23, 634-643. doi: $10.1016 /$ j.tcb.2013.08.007

Hirokawa, N., Niwa, S., and Tanaka, Y. (2010). Molecular motors in neurons: transport mechanisms and roles in brain function, development and disease. Neuron 68, 610-638. doi: 10.1016/j.neuron.2010. 09.039

Hirokawa, N., and Noda, Y. (2008). Intracellular transport and kinesin superfamily proteins, KIFs: structure, function and dynamics. Physiol. Rev. 88, 1089-1118. doi: 10.1152/physrev.00023.2007

Hirokawa, N., Noda, Y., Tanaka, Y., and Niwa, S. (2009). Kinesin superfamily motor proteins and intracellular transport. Nat. Rev. Mol. Cell Biol. 10, 682-696. doi: 10.1038/nrm2774

Holt, C. E., and Schuman, E. M. (2013). The central dogma decentralized: new perspectives on RNA function and local translation in neurons. Neuron 80 , 648-657. doi: 10.1016/j.neuron.2013.10.036

Huber, K. M., Kayser, M. S., and Bear, M. F. (2000). Role for rapid dendritic protein synthesis in hippocampal mGluR-dependent long-term depression. Science 288, 1254-1257. doi: 10.1126/science.288.54 69.1254

Hughes, R. M., Bolger, S., Tapadia, H., and Tucker, C. L. (2012). Light-mediated control of DNA transcription in yeast. Methods 58, 385-391. doi: 10.1016/j. ymeth.2012.08.004 
Hughes, R. M., Freeman, D. J., Lamb, K. N., Pollet, R. M., Smith, W. J., and Lawrence, D. S. (2015). Optogenetic apoptosis: light-triggered cell death. Angew. Chem. Int. Ed. Engl. 54, 12064-12068. doi: 10.1002/anie.2015 06346

Ichimura, T., Wakamiya-Tsuruta, A., Itagaki, C., Taoka, M., Hayano, T., Natsume, T., et al. (2002). Phosphorylation-dependent interaction of kinesin light chain 2 and the 14-3-3 protein. Biochemistry 41, 5566-5572. doi: 10.1021/bi015946f

Idevall-Hagren, O., Dickson, E. J., Hille, B., Toomre, D. K., and De Camilli, P. (2012). Optogenetic control of phosphoinositide metabolism. Proc. Natl. Acad. Sci. U S A 109, E2316-E2323. doi: 10.3410/f.717953724.7934 63137

Inoue, T., Heo, W. D., Grimley, J. S., Wandless, T. J., and Meyer, T. (2005). An inducible translocation strategy to rapidly activate and inhibit small GTPase signaling pathways. Nat. Methods 2, 415-418. doi: 10.1038/ nmeth763

Kaasik, A., Safiulina, D., Choubey, V., Kuum, M., Zharkovsky, A., and Veksler, V. (2007). Mitochondrial swelling impairs the transport of organelles in cerebellar granule neurons. J. Biol. Chem. 282, 32821-32826. doi: 10.1074/jbc. M702295200

Kakumoto, T., and Nakata, T. (2013). Optogenetic control of PIP3: PIP3 is sufficient to induce the actin-based active part of growth cones and is regulated via endocytosis. PLoS One 8:e70861. doi: 10.1371/journal.pone.00 70861

Kapitein, L. C., Schlager, M. A., van der Zwan, W. A., Wulf, P. S., Keijzer, N., and Hoogenraad, C. C. (2010). Probing intracellular motor protein activity using an inducible cargo trafficking assay. Biophys. J. 99, 2143-2152. doi: 10.1016/j.bpj. 2010.07.055

Karginov, A. V., Zou, Y., Shirvanyants, D., Kota, P., Dokholyan, N. V., Young, D. D., et al. (2011). Light regulation of protein dimerization and kinase activity in living cells using photocaged rapamycin and engineered FKBP. J. Am. Chem. Soc. 133, 420-423. doi: 10.1021/ja109630v

Kawano, F., Suzuki, H., Furuya, A., and Sato, M. (2015). Engineered pairs of distinct photoswitches for optogenetic control of cellular proteins. Nat. Commun. 6:6256. doi: 10.1038/ncomms7256

Kennedy, M. J., and Ehlers, M. D. (2006). Organelles and trafficking machinery for postsynaptic plasticity. Annu. Rev. Neurosci. 29, 325-362. doi: 10.1146/annurev.neuro.29.051605.112808

Kennedy, M. J., Hughes, R. M., Peteya, L. A., Schwartz, J. W., Ehlers, M. D., and Tucker, C. L. (2010). Rapid blue-light-mediated induction of protein interactions in living cells. Nat. Methods 7, 973-975. doi: 10.1038/nmeth. 1524

Kevenaar, J. T., and Hoogenraad, C. C. (2015). The axonal cytoskeleton: from organization to function. Front. Mol. Neurosci. 8:44. doi: 10.3389/fnmol.2015. 00044

Kim, N., Kim, J. M., Lee, M., Kim, C. Y., Chang, K. Y., and Heo, W. D. (2014). Spatiotemporal control of fibroblast growth factor receptor signals by blue light. Chem. Biol. 21, 903-912. doi: 10.1016/j.chembiol.2014. 05.013

Kim, B., and Lin, M. Z. (2013). Optobiology: optical control of biological processes via protein engineering. Biochem. Soc. Trans. 41, 1183-1188. doi: 10.1042/BST20130150

Kim, T. I., McCall, J. G., Jung, Y. H., Huang, X., Siuda, E. R., Li, Y., et al. (2013). Injectable, cellular-scale optoelectronics with applications for wireless optogenetics. Science 340, 211-216. doi: 10.1126/science.1232437

Kneussel, M., and Loebrich, S. (2007). Trafficking and synaptic anchoring of ionotropic inhibitory neurotransmitter receptors. Biol. Cell 99, 297-309. doi: 10.1042/bc20060120

Konermann, S., Brigham, M. D., Trevino, A. E., Hsu, P. D., Heidenreich, M., Cong, L., et al. (2013). Optical control of mammalian endogenous transcription and epigenetic states. Nature 500, 472-476. doi: 10.1038/nature 12466

Krishnamurthy, V. V., Khamo, J. S., Mei, W., Turgeon, A. J., Ashraf, H. M., Mondal, P., et al. (2016). Reversible optogenetic control of kinase activity during differentiation and embryonic development. Development 143, 4085-4094. doi: 10.1242/dev.140889

Lasek, R. J. (1967). Bidirectional transport of radioactively labelled axoplasmic components. Nature 216, 1212-1214. doi: 10.1038/2161212a0
Lau, C. G., and Zukin, R. S. (2007). NMDA receptor trafficking in synaptic plasticity and neuropsychiatric disorders. Nat. Rev. Neurosci. 8, 413-426. doi: $10.1038 / \mathrm{nrn} 2153$

Lee, S., Park, H., Kyung, T., Kim, N. Y., Kim, S., Kim, J., et al. (2014). Reversible protein inactivation by optogenetic trapping in cells. Nat. Methods 11, 633-636. doi: $10.1038 /$ nmeth. 2940

Levskaya, A., Weiner, O. D., Lim, W. A., and Voigt, C. A. (2009). Spatiotemporal control of cell signalling using a light-switchable protein interaction. Nature 461, 997-1001. doi: 10.1038/nature08446

Liu, H., Gomez, G., Lin, S., and Lin, C. (2012). Optogenetic control of transcription in zebrafish. PLoS One 7:e50738. doi: 10.1371/journal.pone.00 50738

MacAskill, A. F., Atkin, T. A., and Kittler, J. T. (2010). Mitochondrial trafficking and the provision of energy and calcium buffering at excitatory synapses. Eur. J. Neurosci. 32, 231-240. doi: 10.1111/j.1460-9568.2010.07345.x

Margeta, M. A., Shen, K., and Grill, B. (2008). Building a synapse: lessons on synaptic specificity and presynaptic assembly from the nematode $C$-elegans. Curr. Opin. Neurobiol. 18, 69-76. doi: 10.1016/j.conb.2008.04.003

McGuire, J. R., Rong, J., Li, S. H., and Li, X. J. (2006). Interaction of huntingtinassociated protein-1 with kinesin light chain: implications in intracellular trafficking in neurons. J. Biol. Chem. 281, 3552-3559. doi: 10.1074/jbc. M509806200

Mills, E., Chen, X., Pham, E., Wong, S., and Truong, K. (2012). Engineering a photoactivated caspase-7 for rapid induction of apoptosis. ACS Synth. Biol. 1, 75-82. doi: 10.1021/sb200008j

Mitchison, T. J., and Cramer, L. P. (1996). Actin-based cell motility and cell locomotion. Cell 84, 371-379. doi: 10.1016/s0092-8674(00)81281-7

Morfini, G. A., Burns, M., Binder, L. I., Kanaan, N. M., LaPointe, N., Bosco, D. A., et al. (2009). Axonal transport defects in neurodegenerative diseases. J. Neurosci. 29, 12776-12786. doi: 10.1523/JNEUROSCI.346309.2009

Motta-Mena, L. B., Reade, A., Mallory, M. J., Glantz, S., Weiner, O. D., Lynch, K. W., et al. (2014). An optogenetic gene expression system with rapid activation and deactivation kinetics. Nat. Chem. Biol. 10, 196-202. doi: 10.1038/nchembio.1430

Mudrakola, H. V., Zhang, K., and Cui, B. (2009). Optically resolving individual microtubules in live axons. Structure 17, 1433-1441. doi: 10.1016/j.str.2009. 09.008

Nakamura, M., Chen, L., Howes, S. C., Schindler, T. D., Nogales, E., and Bryant, Z. (2014). Remote control of myosin and kinesin motors using light-activated gearshifting. Nat. Nanotechnol. 9, 693-697. doi: 10.1038/nnano.2014.147

Ochs, S., Sabri, M. I., and Johnson, J. (1969). Fast transport system of materials in mammalian nerve fibers. Science 163, 686-687. doi: 10.1126/science.163. 3868.686

Olenick, M. A., Tokito, M., Boczkowska, M., Dominguez, R., and Holzbaur, E. L. (2016). Hook adaptors induce unidirectional processive motility by enhancing the dynein-dynactin interaction. J. Biol. Chem. 291, 18239-18251. doi: 10.1074/jbc.M116.738211

Ori-McKenney, K. M., Jan, L. Y., and Jan, Y. N. (2012). Golgi outposts shape dendrite morphology by functioning as sites of acentrosomal microtubule nucleation in neurons. Neuron 76, 921-930. doi: 10.1016/j.neuron.2012.10.008

Pakkenberg, B., Pelvig, D., Marner, L., Bundgaard, M. J., Gundersen, H. J. G., Nyengaard, J. R., et al. (2003). Aging and the human neocortex. Exp. Gerontol. 38, 95-99. doi: 10.1016/s0531-5565(02)00151-1

Povlishock, J. T., and Jenkins, L. W. (1995). Are the pathobiological changes evoked by traumatic brain injury immediate and irreversible? Brain Pathol. 5 , 415-426. doi: 10.1111/j.1750-3639.1995.tb00620.x

Putyrski, M., and Schultz, C. (2012). Protein translocation as a tool: the current rapamycin story. FEBS Lett. 586, 2097-2105. doi: 10.1016/j.febslet.2012.04.061

Rakhit, R., Navarro, R., and Wandless, T. J. (2014). Chemical biology strategies for posttranslational control of protein function. Chem. Biol. 21, 1238-1252. doi: 10.1016/j.chembiol.2014.08.011

Rivera, V. M., Wang, X. R., Wardwell, S., Courage, N. L., Volchuk, A., Keenan, T., et al. (2000). Regulation of protein secretion through controlled aggregation in the endoplasmic reticulum. Science 287, 826-830. doi: 10.1126/science.287. 5454.826

Roberson, E. D., Scearce-Levie, K., Palop, J. J., Yan, F., Cheng, I. H., Wu, T., et al. (2007). Reducing endogenous tau ameliorates amyloid $\beta$-induced deficits in an 
Alzheimer's disease mouse model. Science 316, 750-754. doi: 10.1126/science. 1141736

Roy, S., Zhang, B., Lee, V. M., and Trojanowski, J. Q. (2005). Axonal transport defects: a common theme in neurodegenerative diseases. Acta Neuropathol. 109, 5-13. doi: 10.1007/s00401-004-0952-x

Sadowski, L., Pilecka, I., and Miaczynska, M. (2009). Signaling from endosomes: location makes a difference. Exp. Cell Res. 315, 1601-1609. doi: 10.1016/j.yexcr. 2008.09.021

Schelkle, K. M., Griesbaum, T., Ollech, D., Becht, S., Buckup, T., Hamburger, M., et al. (2015). Light-induced protein dimerization by one- and two-photon activation of gibberellic acid derivatives in living cells. Angew. Chem. Int. Ed. Engl. 54, 2825-2829. doi: 10.1002/anie.201409196

Schlager, M. A., and Hoogenraad, C. C. (2009). Basic mechanisms for recognition and transport of synaptic cargos. Mol. Brain 2:25. doi: 10.1186/17566606-2-25

Sheng, Z. H. (2014). Mitochondrial trafficking and anchoring in neurons: new insight and implications. J. Cell Biol. 204, 1087-1098. doi: 10.1083/jcb. 201312123

Sheng, Z. H., and Cai, Q. (2012). Mitochondrial transport in neurons: impact on synaptic homeostasis and neurodegeneration. Nat. Rev. Neurosci. 13, 77-93. doi: $10.1038 / \mathrm{nrn} 3156$

Sheng, M., and Hoogenraad, C. C. (2007). The postsynaptic architecture of excitatory synapses: a more quantitative view. Annu. Rev. Biochem. 76, 823-847. doi: 10.1146/annurev.biochem.76.060805.160029

Shepherd, J. D., and Huganir, R. L. (2007). The cell biology of synaptic plasticity: AMPA receptor trafficking. Annu. Rev. Cell Dev. Biol. 23, 613-643. doi: 10.1146/annurev.cellbio.23.090506.123516

Shimizu-Sato, S., Huq, E., Tepperman, J. M., and Quail, P. H. (2002). A light-switchable gene promoter system. Nat. Biotechnol. 20, 1041-1044. doi: $10.1038 /$ nbt734

Spillane, M., Ketschek, A., Merianda, T. T., Twiss, J. L., and Gallo, G. (2013). Mitochondria coordinate sites of axon branching through localized intraaxonal protein synthesis. Cell Rep. 5, 1564-1575. doi: 10.1016/j.celrep.2013. 11.022

van Spronsen, M., and Hoogenraad, C. C. (2010). Synapse pathology in psychiatric and neurologic disease. Curr. Neurol. Neurosci. Rep. 10, 207-214. doi: 10.1007/s11910-010-0104-8

van Spronsen, M., Mikhaylova, M., Lipka, J., Schlager, M. A., van den Heuve, D. J., Kuijpers, M., et al. (2013). TRAK/Milton motor-adaptor proteins steer mitochondrial trafficking to axons and dendrites. Neuron 77, 485-502. doi: 10.1016/j.neuron.2012.11.027

Steketee, M. B., Moysidis, S. N., Jin, X. L., Weinstein, J. E., Pita-Thomas, W., Raju, H. B., et al. (2011). Nanoparticle-mediated signaling endosome localization regulates growth cone motility and neurite growth. Proc. Natl. Acad. Sci. U S A 108, 19042-19047. doi: 10.1073/pnas.1019624108

Strickland, D., Lin, Y., Wagner, E., Hope, C. M., Zayner, J., Antoniou, C., et al. (2012). TULIPs: tunable, light-controlled interacting protein tags for cell biology. Nat. Methods 9, 379-384. doi: 10.1038/nmeth.1904

Südhof, T. C. (2008). Neuroligins and neurexins link synaptic function to cognitive disease. Nature 455, 903-911. doi: 10.1038/nature07456

Tani, T., Miyamoto, Y., Fujimori, K. E., Taguchi, T., Yanagida, T., Sako, Y., et al. (2005). Trafficking of a ligand-receptor complex on the growth cones as an essential step for the uptake of nerve growth factor at the distal end of the axon: a single-molecule analysis. J. Neurosci. 25, 2181-2191. doi: 10.1523/JNEUROSCI.4570-04.2005

Taslimi, A., Vrana, J. D., Chen, D., Borinskaya, S., Mayer, B. J., Kennedy, M. J., et al. (2014). An optimized optogenetic clustering tool for probing protein interaction and function. Nat. Commun. 5:4925. doi: 10.1038/ncomms5925

Taylor, A. M., Blurton-Jones, M., Rhee, S. W., Cribbs, D. H., Cotman, C. W., and Jeon, N. L. (2005). A microfluidic culture platform for CNS axonal injury, regeneration and transport. Nat. Methods 2, 599-605. doi: 10.1038/ nmeth777

Tischer, D., and Weiner, O. D. (2014). Illuminating cell signalling with optogenetic tools. Nat. Rev. Mol. Cell Biol. 15, 551-558. doi: 10.1038/nrm3837

Tischfield, M. A., Cederquist, G. Y., Gupta, M. L. Jr., and Engle, E. C. (2011). Phenotypic spectrum of the tubulin-related disorders and functional implications of disease-causing mutations. Curr. Opin. Genet. Dev. 21, 286-294. doi: $10.1016 /$ j.gde.2011.01.003
Toettcher, J. E., Gong, D. Q., Lim, W. A., and Weiner, O. D. (2011). Light control of plasma membrane recruitment using the phy-pif system. Methods Enzymol. 497, 409-423. doi: 10.1016/B978-0-12-385075-1.00017-2

Tucker, C. L. (2012). Manipulating cellular processes using optical control of protein-protein interactions. Prog. Brain Res. 196, 95-117. doi: 10.1016/B9780-444-59426-6.00006-9

Tyszkiewicz, A. B., and Muir, T. W. (2008). Activation of protein splicing with light in yeast. Nat. Methods 5, 303-305. doi: 10.1038/nmeth.1189

Umeda, N., Ueno, T., Pohlmeyer, C., Nagano, T., and Inoue, T. (2011). A photocleavable rapamycin conjugate for spatiotemporal control of small GTPase activity. J. Am. Chem. Soc. 133, 12-14. doi: 10.1021/ja108258d

Vagnoni, A., Rodriguez, L., Manser, C., De Vos, K. J., and Miller, C. C. J. (2011). Phosphorylation of kinesin light chain 1 at serine 460 modulates binding and trafficking of calsyntenin-1. J. Cell Sci. 124, 1032-1042. doi: 10.1242/jcs. 075168

Vale, R. D. (2003). The molecular motor toolbox for intracellular transport. Cell 112, 467-480. doi: 10.1016/s0092-8674(03)00111-9

Vallee, R. B., and Bloom, G. S. (1991). Mechanisms of fast and slow axonaltransport. Annu. Rev. Neurosci. 14, 59-92. doi: 10.1146/annurev.neuro. 14.1.59

De Vos, K. J., Grierson, A. J., Ackerley, S., and Miller, C. C. (2008). Role of axonal transport in neurodegenerative diseases. Annu. Rev. Neurosci. 31, 151-173. doi: 10.1146/annurev.neuro.31.061307.090711

Voss, S., Klewer, L., and Wu, Y. W. (2015). Chemically induced dimerization: reversible and spatiotemporal control of protein function in cells. Curr. Opin. Chem. Biol. 28, 194-201. doi: 10.1016/j.cbpa.2015. 09.003

Vossel, K. A., Zhang, K., Brodbeck, J., Daub, A. C., Sharma, P., Finkbeiner, S., et al. (2010). Tau reduction prevents $A \beta$-induced defects in axonal transport. Science 330:198. doi: 10.1126/science.1194653

Wright, C. W., Guo, Z. F., and Liang, F. S. (2015). Light control of cellular processes by using photocaged abscisic acid. Chembiochem 16, 254-261. doi: 10.1002/cbic.201402576

Wu, Y. I., Frey, D., Lungu, O. I., Jaehrig, A., Schlichting, I., Kuhlman, B., et al. (2009). A genetically encoded photoactivatable Rac controls the motility of living cells. Nature 461, 104-108. doi: 10.1038/nature 08241

Xu, K., Zhong, G. S., and Zhuang, X. W. (2013). Actin, spectrin and associated proteins form a periodic cytoskeletal structure in axons. Science 339, 452-456. doi: $10.1126 /$ science. 1232251

Yadav, S., and Linstedt, A. D. (2011). Golgi positioning. Cold Spring Harb. Perspect. Biol. 3:a005322. doi: 10.1101/cshperspect.a005322

Yazawa, M., Sadaghiani, A. M., Hsueh, B., and Dolmetsch, R. E. (2009). Induction of protein-protein interactions in live cells using light. Nat. Biotechnol. 27, 941-945. doi: 10.1038/nbt.1569

Yuan, A. D., Rao, M. V., Veeranna, and Nixon, R. A. (2012). Neurofilaments at a glance. J. Cell Sci. 125, 3257-3263. doi: 10.1242/jcs.104729

Yumerefendi, H., Lerner, A. M., Zimmerman, S. P., Hahn, K., Bear, J. E., Strahl, B. D., et al. (2016). Light-induced nuclear export reveals rapid dynamics of epigenetic modifications. Nat. Chem. Biol. 12, 399-401. doi: $10.1038 /$ nchembio. 2068

Zajac, A. L., Goldman, Y. E., Holzbaur, E. L. F., and Ostap, E. M. (2013). Local cytoskeletal and organelle interactions impact molecular-motor-driven early endosomal trafficking. Curr. Biol. 23, 1173-1180. doi: 10.1016/j.cub.2013. 05.015

Zala, D., Hinckelmann, M. V., Yu, H., Lyra da Cunha, M. M., Liot, G., Cordelieres, F. P., et al. (2013). Vesicular glycolysis provides on-board energy for fast axonal transport. Cell 152, 479-491. doi: 10.1016/j.cell.2012. 12.029

Zeng, G. H., Zhang, R. S., Xuan, W. M., Wang, W., and Liang, F. S. (2015). Constructing de novo $\mathrm{H} 2 \mathrm{O} 2$ signaling via induced protein proximity. Acs Chem. Biol. 10, 1404-1410. doi: 10.1021/acschembio. $5 \mathrm{~b} 00170$

Zhang, K., and Cui, B. X. (2015). Optogenetic control of intracellular signaling pathways. Trends Biotechnol. 33, 92-100. doi: 10.1016/j.tibtech.2014. 11.007

Zhang, K., Duan, L., Ong, Q., Lin, Z., Varman, P., Sung, K., et al. (2014). Light-mediated kinetic control reveals the temporal effect of the 
Raf/MEK/ERK pathway in PC12 cell neurite outgrowth. PLoS One 9:e92917. doi: 10.1371/journal.pone.0092917

Zhang, K., Osakada, Y., Xie, W., and Cui, B. (2011). Automated image analysis for tracking cargo transport in axons. Microsc. Res. Tech. 74, 605-613. doi: 10.1002/jemt.20934

Zhou, X. X., Chung, H. K., Lam, A. J., and Lin, M. Z. (2012). Optical control of protein activity by fluorescent protein domains. Science 338, 810-814. doi: $10.1126 /$ science. 1226854

Zimmermann, M., Cal, R., Janett, E., Hoffmann, V., Bochet, C. G., Constable, E., et al. (2014). Cell- permeant and photocleavable chemical inducer of dimerization. Angew. Chem. Int. Ed. Engl. 53, 4717-4720. doi: 10.1002/anie. 201310969

Ziv, N. E., and Garner, C. C. (2004). Cellular and molecular mechanisms of presynaptic assembly. Nat. Rev. Neurosci. 5, 385-399. doi: 10.1038/ nrn1370
Zoltowski, B. D., and Gardner, K. H. (2011). Tripping the light fantastic: blue-light photoreceptors as examples of environmentally modulated protein-protein interactions. Biochemistry 50, 4-16. doi: 10.1021/bi101665s

Conflict of Interest Statement: The authors declare that the research was conducted in the absence of any commercial or financial relationships that could be construed as a potential conflict of interest.

Copyright (c) 2017 Mondal, Khamo, Krishnamurthy, Cai and Zhang. This is an open-access article distributed under the terms of the Creative Commons Attribution License (CC BY). The use, distribution and reproduction in other forums is permitted, provided the original author(s) or licensor are credited and that the original publication in this journal is cited, in accordance with accepted academic practice. No use, distribution or reproduction is permitted which does not comply with these terms. 